\title{
Learning Gain using a game improve pharmacology knowledge in two transnational HE institutes
}

\author{
Sarah Aynsley ${ }^{1}$, Pathiyil Ravi Shankar ${ }^{2}$, Russell Crawford ${ }^{1}$ \\ ${ }^{1}$ Keele Medical School and Keele Institute for Innovation and Teaching Excellence, Keele \\ University Keele Staffordshire, United Kingdom. ${ }^{2}$ American International Medical \\ University, St. Lucia
}

\begin{abstract}
Gamification in higher education has been shown to provide a diverse range of learning opportunities for higher education practitioners as well as students. Building on our research exploring the benefits of using a cardbased, role-playing team game called "Braincept ${ }^{T M}$ " to aid pharmacology learning for medical students, we now test the reproducibility of our novel finding that this game leads to appreciable and sustained learning gains in medical students from two different higher education institutes. Here we present student feedback, thematic analysis and quantitative pre-and posttest data collected from students who played Braincept ${ }^{T M}$. Our data shows that this style of gamified learning has a reproducible positive effect on student pharmacological knowledge as well as measurable learning gains post-game play in both cohorts of students leading us to conclude that gamification of pharmacology learning may be a pedagogically valuable transnational educational intervention.
\end{abstract}

Keywords: Gamification; pedagogy; pharmacology; learning and teaching; confidence. 


\section{Introduction}

So called, "serious games" have been established in the last decade as having positive effects on both learner engagement and learning gain (Aynsley et al, 2017 and 2018). Despite these established positive impacts, the precise combination of game-based variables that lead to success are still relatively unknown within the higher education context although increasingly, employability related skills are being recognised as a critical benefit of serious game play (Dascalu et al, 2016; Moffat et al, 2015). Braincept ${ }^{\mathrm{TM}}$ is an educational card-based, team role-playing game that we created to aid improvement in developing pharmacology knowledge (Aynsley et al, 2017). In refining our approach through interactive gamification of learning, we use our game to expand students' current knowledge of and confidence with, pharmacological principles in an educational theoryinformed way (Nevin et al, 2014; Iosup and Epema, 2014). Braincept ${ }^{\mathrm{TM}}$ allows up to 5 students to tackle a series of pharmacology-based patient scenarios as a self-directed team without needing a specialist tutor to be present, with the ultimate goal of encouraging learners to link drug names with their primary mechanism(s) of action and common side effect(s) as well as increase their confidence in handling this knowledge (Aynsley et al, 2017). Our aim in the present study was two-fold:

- To provide longitudinal data to test the reproducibility of our previous finding of measurable learning gain through play in an entirely different cohort of medical students within our own UK-based institute.

- To repeat this experimental design with a small cohort (8) of international medical students attending the American International Medical University and determine if measurable learning gains are reproducible in a transnational context.

The potential findings from our work addressing these aims will inform how we build upon the pedagogic and social development skills that our gamified approach to pharmacology learning, as well as proffer pilot data exploring the transferability of this approach transnationally to aid medical student education more widely.

Description of the play mechanic of Braincept ${ }^{\mathrm{TM}}$ has been previously described (Aynsley et al, 2017). Pre- and Post-gameplay, all students were asked to complete our anonymous evaluation questionnaire. This question instrument comprised a 5-point Likert scale with space for free-text comments to collect perceptual data before and after playing the game. Free-text comments were also sought to support the validity of the Likert data and to allow participants to qualify their opinions (Likert, 1932). Learning gain was assessed immediately pre- and post-game and tested again 3 days post-game, using short pharmacology quizzes consisting three different questions within a conserved format: Q1 For a given drug what is the mechanism of action?; Q2 - For a given mechanism of action, name a drug?; Q3 - What are the main side effects of a given drug?. 


\section{Results}

A For a given drug what is the mechanism

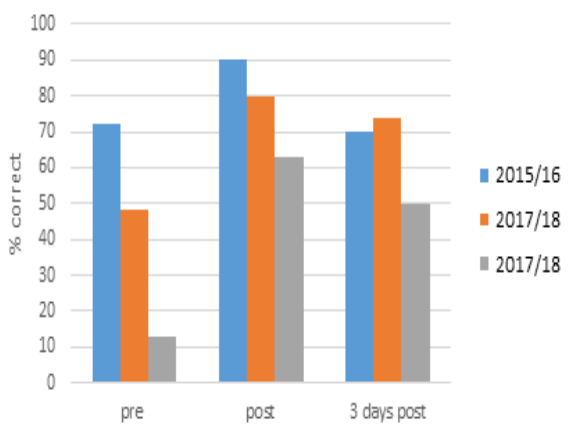

C Main side effects of given drug

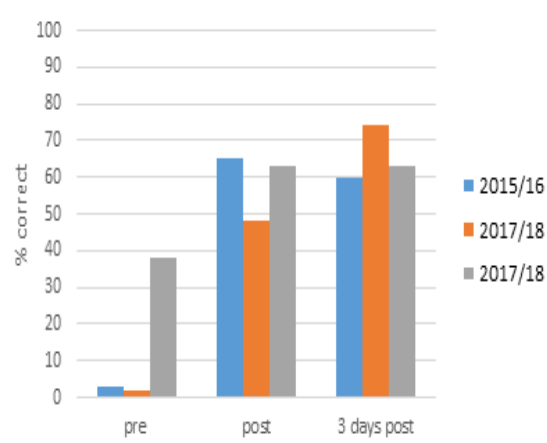

B For the given mechanism name a drug

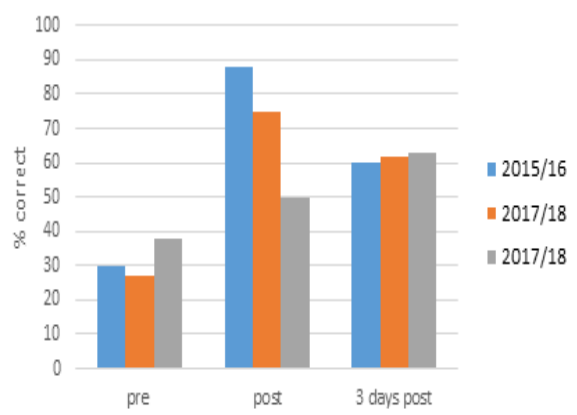

Figure 1:

In each panel, the $Y$ axis of these data shows the percentage $(\%)$ correct answers to the pharmacology tests either pregame play, immediately post game play or 3 days post gameplay, as indicated by the XAxis. Colours denote cohorts of students, with blue representing the data from the 2015/16 cohort of Keele medical students, Orange representing the data from the 2017/18 cohort of Keele medical students and grey representing the data from the American International Medical University students. It should be noted that all students were at a comparable level (second year) of their studies. Each panel represents the data for one of three questions; $A$ - For a given drug, what is the mechanism of action; $B$ - for a given mechanism of action, namea drug and finally, $C$ - what are the main side effects of a given drug.

Figure 1. Learning Gain Data 
Table 1. Free-text Data and representative comments

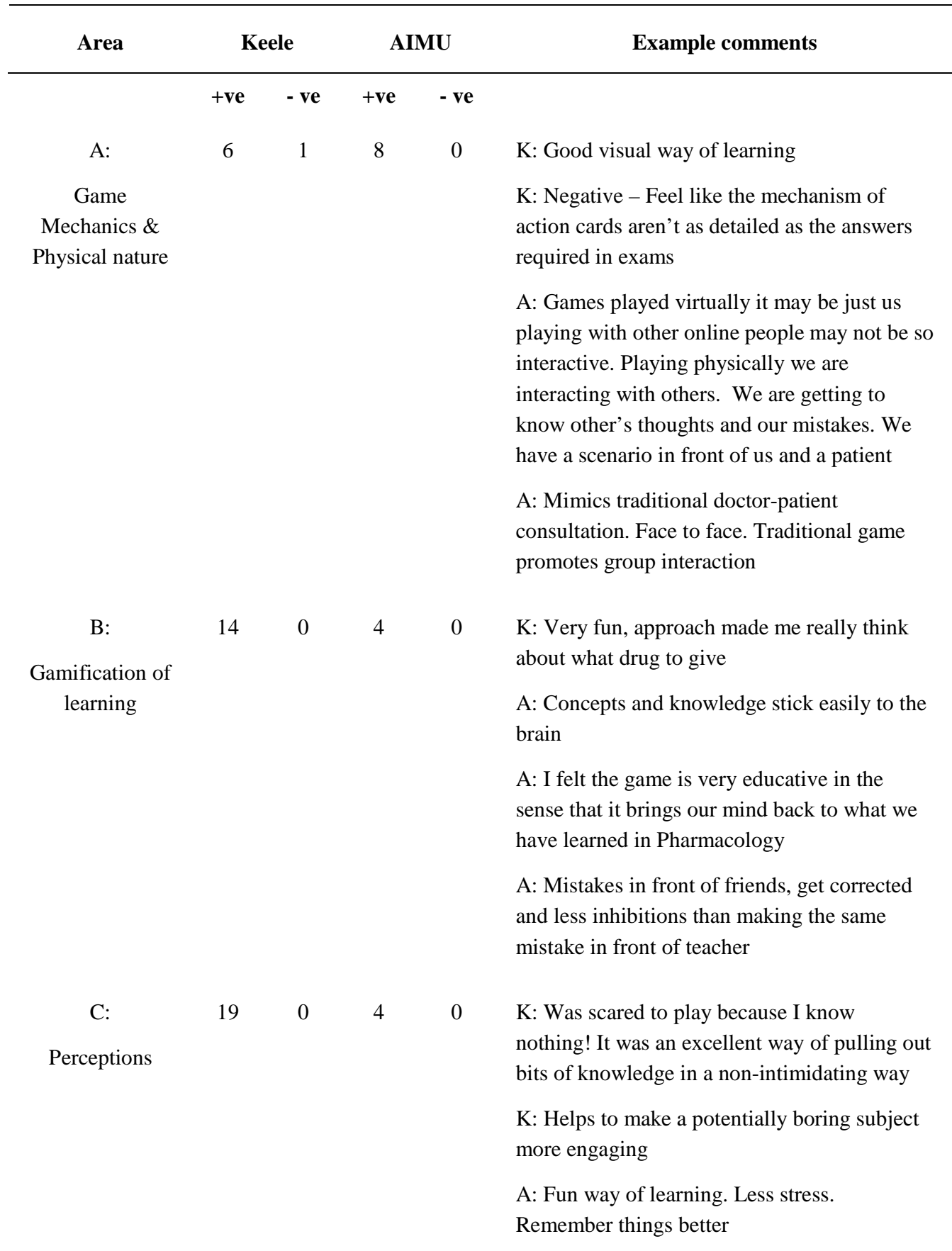


D:

\section{Game use in} learning

\begin{abstract}
9
\end{abstract}
0

4

0

$\mathrm{K}$ : Would be good if matched with drugs from the PBL cases $\rightarrow$ play each week building in new drugs.

A: This helps to revise what we had learned in class. May be better than integration seminars because here everyone is active, talking between themselves and playing. You may need to have attended lectures and know about what you are going to play.

A: Use it to revise what I have learned. Lectures may be long and may be difficult to fully concentrate

E: $\quad 1 \quad 0 \quad 2 \quad 0$

Clinical Context

/ Role-play applying the pharmacology in a clinical setting
K: Really enjoyed this game! Felt like in response to an actual patient/disease

A: Does it in a clinical setting as we are not going to the hospital.. Feels like you are in front of patient and if you have a drug to prescribe you have to know what the drug does.

A: I felt the game is very educative in the sense that it brings our mind back to what we have learned in Pharmacology. It puts us in the position of a future health professional. We are in a practical setting where we have to face the patient.

\section{Discussion}

Figure 1 presents the learning gain data from 2017/18 cohorts of both Keele (Orange) and AIMU students (Grey) when compared to our previous data from 2015/16 (Blue). Interestingly, we observed learning gain in each of three styles of exploratory question we asked to test pharmacology knowledge (for a given drug, what is the mechanism of action; for a given mechanism of action, name a drug; what are the main side effects of a given drug) when comparing pre- and immediately post-game play, with upward deflections observed in each case. This indicates to us that learning benefits from playing Braincept ${ }^{\mathrm{TM}}$ are reproducible in successive cohorts of Keele medical students, convincingly removing inter-cohort variability as a possible major confounding factor in determining the validity of 
improving knowledge using a gamified approach. Data from the AIMU students also showed comparable learning gains when comparing pre- and immediately post-game play. Whilst learning gain measured immediately post-game play is a useful metric of both improvement in short term learning gain as well as engagement with our gamified approach to learning, we were also interested in testing longer term retention of knowledge to explore this context. The third cluster of bars in each of the panels (A, B and C) of Figure 1 reveal that retention of testable pharmacology knowledge three days later (with no access to the game during that time) remained higher than pre-game play percentages across all three question types and was observed in both cohorts (Keele and AIMU) of students. There remains two plausible explanations of the observed learning gains in Figure 1, namely that a single play session with Braincept ${ }^{\mathrm{TM}}$ is sufficient to allow synthesis/consolidation of pharmacology learning and improve longer-term retention sustained over 3 days, as evidenced in their testable scores. The alternative explanation is that students are using the game to self-evaluate learning gaps and then engaging in private study to increase their knowledge, reflected in an increased test score after 3 days. From a pedagogic standpoint, we suspect the latter is true and our free-text data would seem to support this assertion. We would therefore hypothesis that our gamified approach constitutes a transformative pedagogy, which we define as "learner understanding enhanced by the social, collaborative aspects” of playing the game, which offers Braincept ${ }^{\mathrm{TM}}$ players the opportunity to enhance discussion-based information handling and self-evaluation skills via shared understanding (Dolan et al, 2013). The American International Medical University (AIMU) is an offshore Caribbean medical school (OCMS) located in Saint Lucia admitting students predominantly from India, Nigeria, and other countries to the undergraduate medical (MD) program. The institution follows a traditional discipline-based curriculum though recently modifications to teaching-learning at the institution have been carried out (Shankar \& Dakubo, 2018). Pharmacology is taught during the fourth semester of the MD program along with systemic pathology and physical diagnosis. At most OCMS a semester of study is of 15 weeks duration. Students complete 5 semesters of the basic sciences in Saint Lucia. Problembased learning is not a part of the curriculum though clinical cases are used. Like other OCMS the school does not have its own clinical hospital and students do their clinical rotations at hospitals in the United States and the Caribbean (Shankar et al., 2017). There are challenges in providing clinical exposure to the students. Lectures are the predominant teaching-learning method used accounting for over $90 \%$ of curricular time though other methods have also been introduced. Despite various challenges small group sessions are conducted regularly in pharmacology with the emphasis being on teaching medical students to use essential medicines rationally (Shankar, 2018). Students are introduced to personal drug selection, patient counselling, pharmaceutical promotion and social issues in use of medicines among other topics. Some OCMS are switching to an integrated curriculum while many others still follow a traditional curriculum. Due to low faculty numbers and 
other reasons, lectures continue to be the dominant method of teaching-learning. Xavier University School of Medicine in Aruba shifted to an integrated organ-system based curriculum in 2014 (Shankar, 2014). Some other OCMS are also having an integrated basic sciences curriculum. The other schools in Saint Lucia follow a traditional discipline-based curriculum. Our finding resulted in the emergence of five themes across the free-text data along with a couple of suggestions on ways to improve the game. These five themes were:

A: Game Mechanics and the physical nature of the game: Our previous research explored perceptions of the digital vs. live-play formats applied to serious gaming and whilst we acknowledge that each mode of delivery has its own pros and cons, the feedback from our players indicated overwhelmingly positively that they values the interactive and discursive nature of the game as a way to promote interaction in small groups. $\boldsymbol{B}$ : Gamification of Learning and C: Perceptions: Our recent work has alluded to how critical the element of "fun" is in so-called "serious" games (Aynsley et al, 2018) and we were pleased to also find this to be the case for the Braincept ${ }^{\mathrm{TM}}$ game, with all players positively identifying this was conducive to both easier retention of knowledge (further supported by our data in Figure 1) as well as reducing inhibitions or risk aversion by proxy of the game play mechanic, which we interpret as an inherent flexibility in using a gamebased approach to support student learning preferences (Walsh, 2014). D: Game use in learning: Again, this theme had elements of seeing the game as a useful revision tool as well as a mechanism to enhance small group engagement, in a universally positive response from both student cohorts sharing ideas of engagement and active learning as aspects to Braincept $^{\mathrm{TM}}$ that they valued. What was also apparent from the feedback was that the game offered a different pedagogic style of learning, that was perceived as being a positive different from more traditional lecture or seminar-based learning modes. E: Clinical

Context / Simulation: One minor theme to emerge from the student feedback comments was that of the authenticity and role-play aspects of the game, which were perceived to be of value, with students sharing that they liked both the urgency of the game play mechanic (ie, to treat a "patient”) as well as the opportunity to role-play within a pseudo-clinical thematic game environment. This could also be of benefit as an unintended finding of playing the game, where there may be a small dimension of aiding in formation of learner professional (and in this case, clinical) identity made possible by the thematic nature of the game and our future work will look to explore this more rigorously. In conclusion, we interpret our finding from this work as convincing evidence that our gamified approach to pharmacology learning is a transferable pedagogic model of intervention that reproducibly works in a transnational context despite having different curricula. 


\section{References}

Aynsley S, Crawford R. (2017) Pilot evaluation of medical student perception of a novel pharmacology-based role-play game: Braincept. Educ. Health 2017;30:97-8

Aynsley, SA, Nathawat, K \& Crawford, RM (2018) Evaluating student perceptions of using a game-based approach to aid learning: Braincept, Higher Education Pedagogies, 3:1, 70-81.

Dascalu, M. I., Tesila, B., \& Nedelcu, R. A. (2016). Enhancing Employability Through eLearning Communities: From Myth to Reality. In State-of-the-Art and Future Directions of Smart Learning (pp. 309-313). Springer Singapore.

Dolan, P., Leat, D., Mazzoli Smith, L., Mitra, S., Todd, L., \& Wall, K. (2013). Selforganised learning environments (SOLEs) in an English school: an example of transformative pedagogy?. Online Education Research Journal, 3(11).

Iosup, A., \& Epema, D. (2014, March). An experience report on using gamification in technical higher education. In Proceedings of the 45th ACM technical symposium on Computer science education (pp. 27-32). ACM.

Likert, R. (1932). A Technique for the Measurement of Attitudes. Archives of Psychology, 140, 1-55.

Moffat, D., Farrell, D., Gardiner, B., McCulloch, A., \& Fairlie, F. (2015, October). A Serious Game to Give Students Careers Advice, Awareness and Action. In ECEL201514th European Conference on e-Learning: ECEl2015 (p. 396). Academic Conferences and publishing limited.

Nevin, C. R., Westfall, A. O., Rodriguez, J. M., Dempsey, D. M., Cherrington, A., Roy, B., \& Willig, J. H. (2014). Gamification as a tool for enhancing graduate medical education. Postgraduate medical journal, postgradmedj-2013.

Shankar PR. Challenges in implementing an integrated curriculum in a Caribbean medical school. Education in Medicine Journal 2014;6(4):E74-E77. DOI: 10.5959/eimj.v6i4.290

Shankar PR, Dakubo G. Utilizing the curriculum committee to strengthen teaching-learning in a medical school. Education in Medicine Journal 2018;10(2):49-54. https://doi. org/10.21315/eimj2018.10.2.6

Shankar PR, Balasubramanium R, Dakubo G. Challenges with regard to undergraduate medical education in offshore Caribbean medical schools. Education in Medicine Journal 2017;9(4):69-75. DOI: 10.5959/eimj.v9i4.579

Shankar PR. Challenges in conducting small group sessions in pharmacology - a Caribbean perspective. Janaki Medical College Journal of Medical Sciences 2018; 6 (2): 60-64. DOI:https://doi.org/10.3126/jmcjms.v6i02.22091.

Walsh, C., Apperley, T., Abbott, C., Albright, J., Alverman, D., Beavis, C., ... \& Wood, D. Reconceptualising gamification: Play and pedagogy. Published online 2014 (http://www.digitalcultureandeducation.com/uncategorized/tulloch_html/) 